\title{
A statistical study of underestimates of wind speeds by VHF radar
}

\author{
L. Thomas, I. Astin, ${ }^{*}$ R. M. Worthington \\ Department of Physics, University of Wales, Aberystwyth, Dyfed, SY23 3BZ, UK
}

Received: 28 May 1996 / Revised: 14 January 1997 / Accepted: 16 January 1997

\begin{abstract}
Comparisons are made between horizontal wind measurements carried out using a VHF-radar system at Aberystwyth $\left(52.4^{\circ} \mathrm{N}, 4.1^{\circ} \mathrm{W}\right)$ and radiosondes launched from Aberporth, some $50 \mathrm{~km}$ to the southwest. The radar wind results are derived from Doppler wind measurements at zenith angles of $6^{\circ}$ in two orthogonal planes and in the vertical direction. Measurements on a total of 398 days over a 2-year period are considered, but the major part of the study involves a statistical analysis of data collected during 75 radiosonde flights selected to minimise the spatial separation of the two sets of measurements. Whereas good agreement is found between the two sets of wind direction, radar-derived wind speeds show underestimates of 4-6\% compared with radiosonde values over the height range $4-14 \mathrm{~km}$. Studies of the characteristics of this discrepancy in wind speeds have concentrated on its directional dependence, the effects of the spatial separation of the two sets of measurements, and the influence of any uncertainty in the radar measurements of vertical velocities. The aspect sensitivity of radar echoes has previously been suggested as a cause of underestimates of wind speeds by VHF radar. The present statistical treatment and case-studies show that an appropriate correction can be applied using estimates of the effective radar beam angle derived from a comparison of echo powers at zenith angles of $4.2^{\circ}$ and $8.5^{\circ}$.
\end{abstract}

\section{Introduction}

During the past two decades considerable attention has been paid to the use of stratospheric-tropospheric radars to improve our understanding of mesoscale processes

\footnotetext{
"Now at the NERC Environmental Systems Science Centre, University of Reading, Whitenights, P.O. Box 227, Reading, RG6 6AB, UK
}

and to contribute to numerical weather forecasts. To date, the use of such radars has been largely limited to individual sites, but networks are presently under study or construction, and even in operation in the USA (Strauch et al., 1984, Seraphin and Dabberdt, 1990) and in Europe (Häsenjager, 1990). The relevant measurements provided by such radars are the height profiles of the horizontal wind vector and vertical velocity, and information on turbulent and layered structures. Previously, operational wind observations have depended on the tracking of weather balloons. It is, therefore, natural in assessing the performance of wind profiler systems to make comparison with radiosonde measurements. Several such comparisons have been carried out at a range of latitudes (Green et al., 1975; Röttger et al., 1978; Warnock et al., 1978; Ecklund et al., 1979; Balsley et al., 1979; Farley et al., 1979; Crane, 1980; Fukao et al., 1982; Larsen, 1983; Weber and Wuertz, 1990; Astin and Thomas, 1991; May, 1993; Steinhagen et al., 1994). However, the majority of these comparisons have been based on radar and radiosonde wind measurements separated by several tens of kilometres and the major discrepancies between these measurements have been attributed to differences in time and space, as demonstrated by intercomparisons of radiosonde measurements (Jasperson, 1982; Kitchen, 1989). In addition, discrepancies might be expected from differences in the sampling procedure used by the two techniques and from errors of measurement. The radiosondes make measurements at various heights at different times and locations whereas radar measurements provide wind velocities over a range of heights simultaneously; the two approaches can be concerned with different spatial and temporal scales; and errors can arise from poor signal-to-noise ratios in the radar signals and from inadequate tracking of radiosondes, both being most serious at the greater heights. Each of these factors could contribute to random differences between the two sets of measurements. However, evidence has also been found for systematic differences between the radar and radiosonde measurements (Kessler et al., 1986; Weber 
and Wuertz, 1990; Astin and Thomas, 1991), the radarbased values being smaller than those derived from balloons. A discrepancy of similar sense has also been reported by Vincent et al. (1987) from a comparison of spaced-antenna measurements of winds and corresponding radiosonde values. However, before this is considered as the same discrepancy as seen in the comparison of radiosonde and radar Doppler-shift measurements, the relationship between the two types of radio-wind measurements needs to be clarified with further tests of the type described by van Baelen et al. (1990). In fact, Vincent et al. (1987) have attributed the discrepancy in their comparison to the fact that the triangle of receiving stations was smaller than the diffraction pattern being observed, and underestimates of wind speed could be expected (Golley and Rossiter, 1970).

In the Doppler-shift method of deriving horizontal winds, measurements with off-vertical beams in two orthogonal planes are combined with corresponding measurements with a vertical beam. Difficulties can then arise from a spatial variation of either the horizontal or vertical wind component, and accordingly small offvertical angles might be favoured. However, a common feature of VHF-radar measurements is the enhanced echo power observed in the vertical direction compared with that in off-vertical directions. Röttger (1981) pointed out that with relatively broad radar beams, this aspect sensitivity of the echo power could cause a discrepancy between the bore-sight radar beam direction and the effective beam direction for relatively small zenith angles, and this could lead to an underestimate of a measured horizontal wind speed. Support for this suggestion was provided by estimates for two days of the horizontal wind component with beam zenith angles of $2^{\circ}-12^{\circ}$ by Tsuda et al. (1986) and by comparisons of radar wind measurements at zenith angles of $4.2^{\circ}, 6^{\circ}$ and $12^{\circ}$ with balloon-based measurements in sets of 20-30 balloons for each zenith angle by Astin and Thomas (1991).

The purpose of the present study has been to examine statistically the underestimate of radar wind speeds from a comparison of wind measurements using a $46.5-\mathrm{MHz}$ radar system at Aberystwyth $\left(52.4^{\circ} \mathrm{N}, 4.1^{\circ} \mathrm{W}\right)$ and radiosondes launched from the UK Meteorological Office station at Aberporth, some $50 \mathrm{~km}$ to the SouthWest. The study is based on measurements near 0600 GMT on week days during the period January 1992-January 1994 and includes a range of climatic conditions. Initially, all available data are considered, but in order to examine the possible effect of the spatial separation of the radar and balloon measurements, attention is also concentrated on balloons which travel within $\pm 20^{\circ}$ of the Aberporth-Aberystwyth direction and also within $5 \mathrm{~km}$ of the radar site. Previous studies have shown that large vertical velocities associated with mountain waves are commonly observed at the radar site (Prichard et al., 1995). The possible influence of such vertical velocities is also examined. The correction for aspect sensitivity of horizontal wind estimates derived using nominal off-vertical beam angles of $6^{\circ}$ has made use of power measurements at zenith angles of $4.2^{\circ}$ and $8.5^{\circ}$ to derive the effective beam angle. Hooper and
Thomas (1995) have demonstrated that a combination of power measurements in the $6^{\circ}$ and vertical directions over-corrects the radar wind estimates.

\section{Radar and radiosonde measurements}

The radar makes use of five transmitters providing a combined peak power of $160 \mathrm{~kW}$ with a maximum duty cycle of 5\%. The antenna array is made up of 400 fourelement Yagis occupying a square of area $1.1 \times 10^{4} \mathrm{~m}^{2}$ orientated so that the sides are $17.3^{\circ}$ anticlockwise from the cardinal compass points. It provides a one-way halfpower beam width of $3^{\circ}$, with a total of 16 possible beam directions. Doppler-shift measurements at zenith angles of $6^{\circ}$ in azimuths $27.7^{\circ}$ and $297.7^{\circ}$ East of North, corresponding to diagonals of the array, and in the zenith direction were used to measure winds. The measurement cycle time was $1.2 \mathrm{~min}$, the spectra being averaged for a period which included the duration of the associated balloon flight, about $30-45 \mathrm{~min}$, to give a mean wind velocity profile. Only radar measurements with a signal-to-noise ratio in excess of $4 \mathrm{~dB}$ were employed. During 1992-1993, the cycle time of measurements was increased to $2.4 \mathrm{~min}$ to include signal power measurements at zenith angles of $4.2^{\circ}$ and $8.5^{\circ}$ in the intermediate azimuth $342.7^{\circ}$ East of North in order to examine the aspect sensitivity of the backscatter and, thereby correct the nominal zenith angle of $6^{\circ}$ in the wind measurements. The balloon wind measurements were based on the Väisälä RS80 system which involves the radar tracking in elevation, azimuth and range of a balloon-borne corner reflector. The 2-year observational period included a total of 474 balloon launches, but owing to difficulties arising from poor signal-to-noise ratios of the radar measurements, inadequate time overlap between balloon and radar measurements and restricted height coverage of certain balloons, the comparison of the two sets of measurements is restricted to 398 balloon flights. The wind velocities were provided at $150-\mathrm{m}$ height intervals and the comparison of radar and radiosonde wind velocities was based on running averages over 3 height intervals for the two series of measurements.

\section{Comparisons of wind profiler and radiosonde measurements}

\subsection{Comparisons on individual days}

Figure 1 shows typical profiles of horizontal wind measured by radiosonde and by radar using vertical and the two $6^{\circ}$ beams on two days in July 1993. These relate to cyclonic conditions associated with a low-pressure system located between Scandinavia and Iceland. Those for 27 July in Fig. 1a show that the radar-based values are smaller than those derived from the radiosonde over the height range $3-8 \mathrm{~km}$ but indicate better agreement at greater heights; those for 29 July in Fig. 1b show a more intermittent discrepancy at all heights. It is to be noted that no steady offset is shown for all heights, as might be 

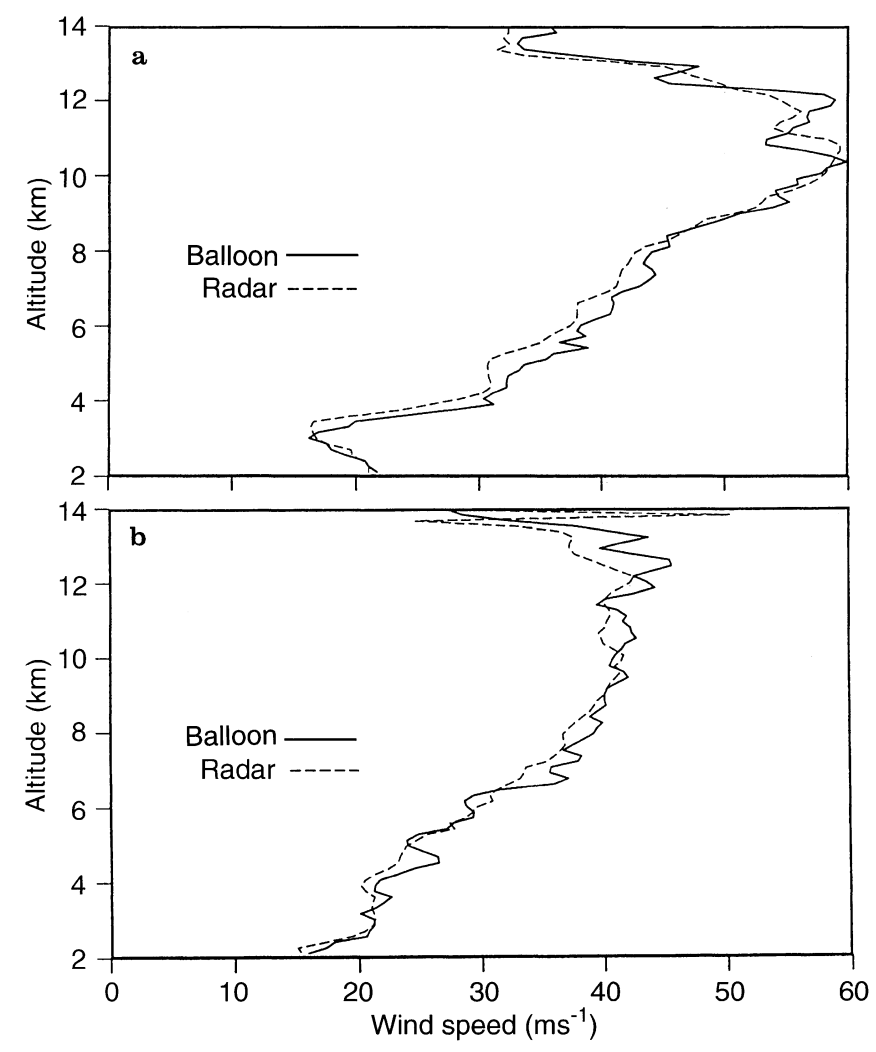

Fig. 1a, b. Profiles of wind speed in the 2-14-km height range derived from radar measurements at Aberystwyth $\left(52.4^{\circ} \mathrm{N}, 4.1^{\circ} \mathrm{W}\right)$ and radiosondes launched from Aberporth, some $50 \mathrm{~km}$ to the SouthWest, near 0600 GMT on a 27 July 1993 and b 29 July 1993

expected for an instrumental error in the pointing angle of the radar beam, and the discrepancies probably arise from a combination of aspect sensitivity and, perhaps, horizontal separation effects.

\subsection{Comparisons based on all data}

The trajectories of all balloons considered in the present study are shown in Fig. 2. It is clear that although the trajectories were distributed over all directions the majority responded to winds from the NW to SW sector. A comparison of speeds at height intervals of 750 $\mathrm{m}$ in the range $4-14 \mathrm{~km}$, derived from all the balloon flights and coordinated radar measurements, is shown in Fig. 3. The regression line of radar wind speed on radiosonde wind speed is arranged to pass through the origin $(0,0)$ and corresponds to a regression coefficient of $0.939 \pm 0.002$ for the total of 5291 points. The outliers can arise from deficiencies in the radar measurements, as illustrated for heights near $14 \mathrm{~km}$ in Fig. $1 \mathrm{~b}$, or from loss of balloon tracking at large ranges. In addition, comparisons carried out by the Meteorological Office of winds observed from radiosondes launched at Aberporth and a site a few kilometres from the radar site have shown rms differences of $3-4 \mathrm{~m} \mathrm{~s}^{-1}$ for balloon separations of $40 \mathrm{~km}$ which implies discrepancies of about $10 \mathrm{~m} \mathrm{~s}^{-1}$ or greater on individual occasions

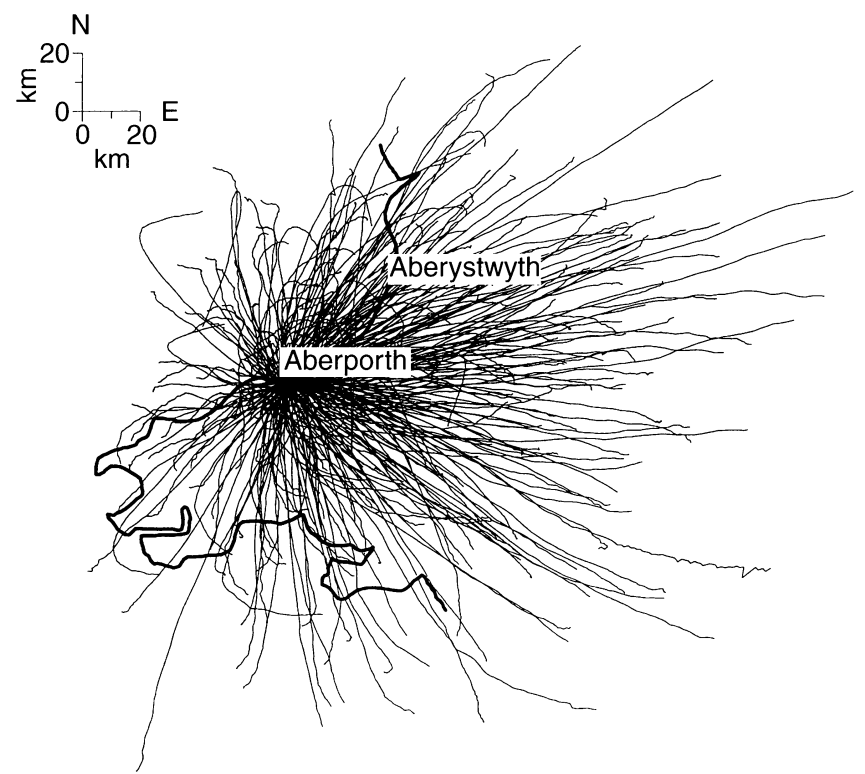

Fig. 2. Trajectories of radiosondes launched from Aberporth near 0600 GMT during 1992-93 used in study

(J. Nash, private communication). The corresponding line, refitted after removal of outliers, is shown in Fig. 4, these outliers being defined as points outside a range of radar wind speeds of 1.66 standard deviations either side of the regression line; for a normal distribution this corresponds to values less than one-quarter of the maximum. The regression coefficient is increased slightly to a value of $0.944 \pm 0.001$ for a total of 5018 points. As noted in Astin and Thomas (1991), for smaller samples

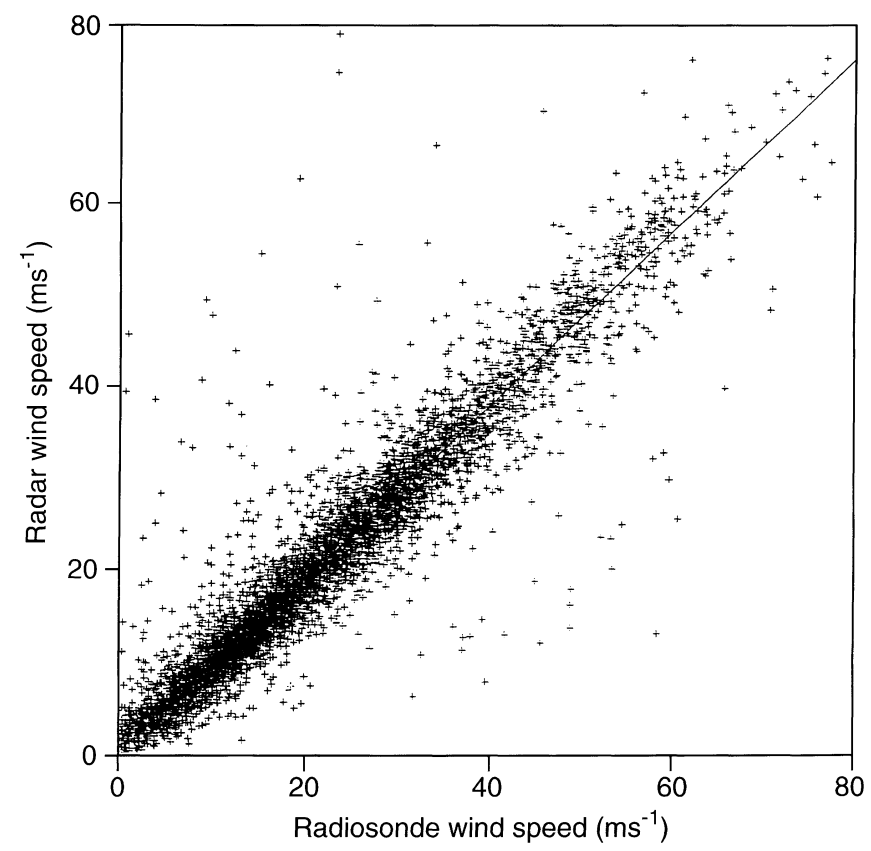

Fig. 3. Comparisons of wind speeds in the 4-14-km height range derived from all simultaneous radar measurements and radiosonde flights. The regression line of radar measurements on radiosonde measurements is shown 


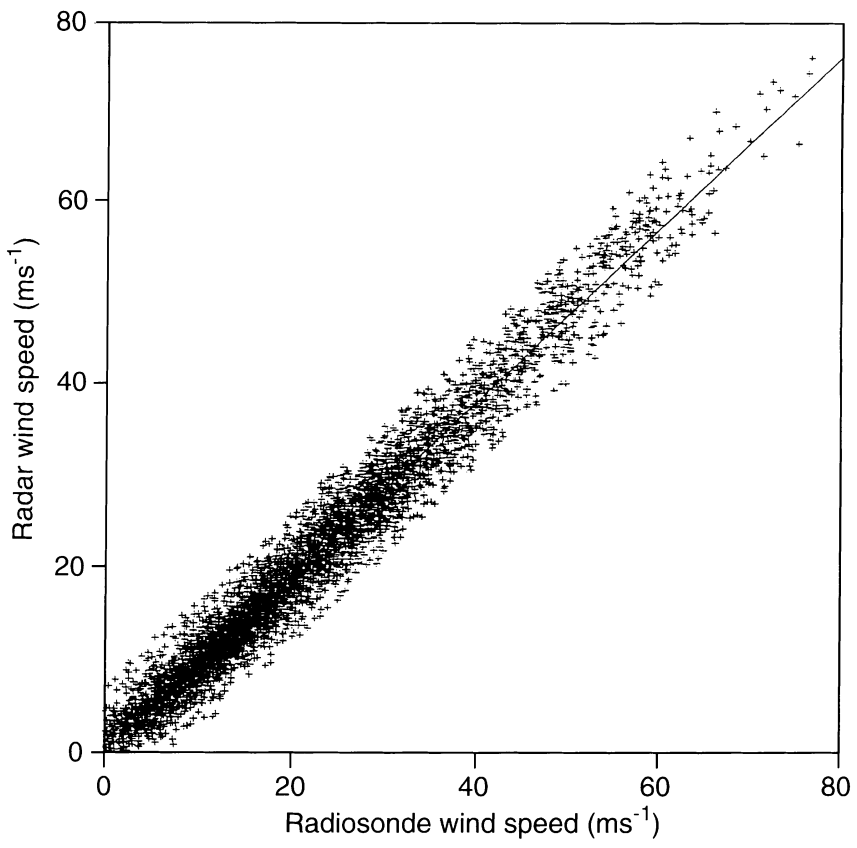

Fig. 4. Comparisons of wind speeds in the 4-14-km height range derived from all simultaneous radar measurements and radiosonde flights, after removal of outliers. The regression line of radar measurements on radiosonde measurements is shown

of data, the comparison of wind directions derived by the two techniques showed very good agreement, both on individual days and statistically, with regression coefficients near unity.

\subsection{Comparison based on data for balloon trajectories within $\pm 20^{\circ}$ of Aberporth-Aberystwyth direction}

In order to examine the possible influence of spatial variations in winds, a similar regression analysis was carried out for days during which the balloons passed within $\pm 20^{\circ}$ of the Aberporth-Aberystwyth direction, corresponding to a horizontal separation of up to $\pm 18 \mathrm{~km}$ about this direction near the radar site. With this selection, a total of 75 days was included in the comparison, and in order to provide a comparable number of data pairs as in Sect. 3.2, wind measurements at $150-\mathrm{m}$ intervals were considered. A comparison for the $4-14-\mathrm{km}$ height range, after outliers have been removed as previously, is shown in Fig. 5. The number and magnitudes of these outliers were substantially smaller than in Fig. 3, as expected from the reduction in the effects of spatial variations believed to be involved in the overall data (Sect. 3.2). The regression line passing through the origin corresponds to a coefficient of 0.956 \pm 0.001 for a total of 4842 points. The magnitude of the improvement of this value compared with that for all balloon directions in Sect. 3.2 would seem to suggest that only a small influence arises from the spatial separation of the two sets of measurements. A still smaller separation of the two sets of measurements was arranged by considering only balloons which passed within $\pm 5 \mathrm{~km}$ of the radar site. The comparison was

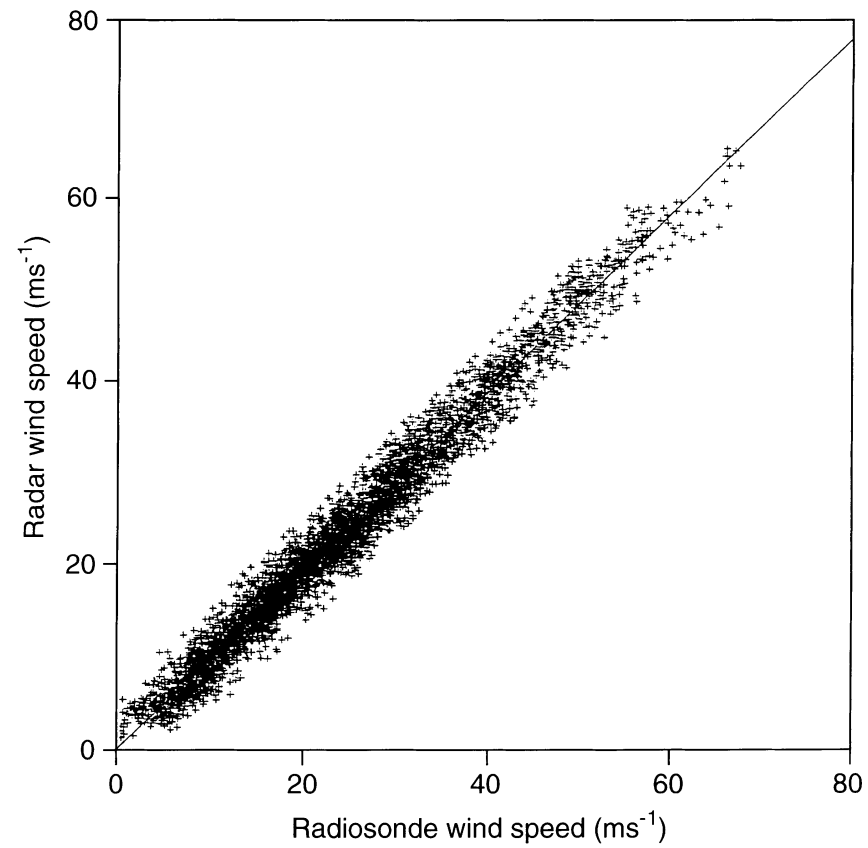

Fig. 5. Comparison of wind speeds in the 4-14-km height range derived from all simultaneous radar measurements and radiosondes passing within $\pm 20^{\circ}$ of the Aberporth-Aberystwyth direction. The regression line of radar measurements on radiosonde measurements is shown

then based on measurements over a very limited range of heights, for which the two sets of measurements agreed in time within 2-3 min. For the regression line passing through the origin, a regression coefficient of $0.965 \pm 0.010$ was obtained for a total of 73 points. The larger standard error obscures any improvement over the figures obtained for the $\pm 20^{\circ}$ range of directions. However, the two sets of figures indicate that even after the effects of spatial separation have been removed there remains an underestimate of wind velocities by the radar, compared with those derived from balloons, of about $4.5 \%$.

\subsection{Dependence of systematic difference on height and direction}

The regression coefficients derived for balloon trajectories within $\pm 20^{\circ}$ of the Aberporth-Aberystwyth direction at heights generally below the tropopause $(4-7 \mathrm{~km})$, above the tropopause $(11-14 \mathrm{~km})$, and at intermediate heights $(7-11 \mathrm{~km})$, together with the results for the total height range 4-14 km referred to in Sect. 3.3, are shown in Table 1. The figures for the lowest and upmost height ranges refer to populations of 1400-1500 points and those for the intermediate range to 1950 points. The regression coefficient results are generally similar, although those for $11-14 \mathrm{~km}$ are slightly larger. On the basis of the results in Sect. 3.3, the greater proximity of the radiosonde and radar measurements at these heights might not be significant, but the greater aspect sensitivity generally observed in the lower stratosphere than the 
Table 1. Regression coefficients for balloons trajectories with $\pm 20^{\circ}$ of Aberporth-Aberystwyth direction

\begin{tabular}{llll}
\hline $\begin{array}{l}\text { Height } \\
\text { Range, km }\end{array}$ & $\begin{array}{l}\text { Total } \\
\text { wind }\end{array}$ & $\begin{array}{l}27.7^{\circ} \mathrm{E} \text { of } \mathrm{N} \\
\text { component }\end{array}$ & $\begin{array}{l}297.7^{\circ} \mathrm{E} \text { of } \mathrm{N} \\
\text { component }\end{array}$ \\
\hline $4-7$ & $0.949 \pm 0.002$ & $0.945 \pm 0.002$ & $0.937 \pm 0.003$ \\
$7-11$ & $0.954 \pm 0.002$ & $0.957 \pm 0.002$ & $0.928 \pm 0.003$ \\
$11-14$ & $0.965 \pm 0.002$ & $0.959 \pm 0.003$ & $0.968 \pm 0.004$ \\
$4-14$ & $0.956 \pm 0.001$ & $0.955 \pm 0.001$ & $0.940 \pm 0.002$ \\
\hline
\end{tabular}

troposphere might be expected to lead to smaller regression coefficients (Sect. 4).

The corresponding regression coefficients for the wind components in the two azimuths of the radar beams (i.e. $27.7^{\circ}$ and $297.7^{\circ}$ East of North) are also included in Table 1. These two latter sets of results agree with each other to within $1.5 \%$, except for those for the $7-11-\mathrm{km}$ range. The larger values are generally shown by the NE components, except for the 11-14-km height range, and it is of interest to note that these are near the selected balloon trajectories and hence represent the larger wind components. The general consistency between the values in the two azimuths is compatible with the good agreement found between the total wind directions recorded in the radar and balloon measurements.

\subsection{Influence of vertical velocity}

Further studies of the measurements for several individual days show that the systematic differences between the wind profiles recorded in the wind and balloon measurements persist even when the vertical velocities measured in the radar soundings are omitted. On several days, marked changes in the vertical velocity are observed with increasing height (e.g. Prichard et al., 1995) but no corresponding changes are noted in the systematic differences between the radar and wind profiles. Again, an analysis of a data sample rather smaller than in Sect. 3.3 shows little difference between the radar horizontal wind velocities derived from Doppler measurements for beam pairs at $6^{\circ}$ zenith angles in NE-SW and NW-SE azimuths, and those obtained from the more usual combination of Doppler measurements at $6^{\circ}$ zenith angles in the NW and NE azimuths and in the vertical direction. On the basis of these tests, it is concluded that any uncertainty in the radar measurements of vertical velocity makes no significant contribution to the difference between radar and balloon measurements of wind velocity.

\section{Influence of aspect sensitivity of radar backscatter}

In order to examine the influence of aspect sensitivity of echoes at $6^{\circ}$ zenith angle in the present study, the effective angle has been estimated, following Hocking et al. (1986), using the expression: $\sin \theta_{\text {eff }}=\sin \theta\left[1+\frac{\sin ^{2} \theta_{o}}{\sin ^{2} \theta_{s}}\right]^{-1}$,

in which it is assumed that the two-way polar diagram of the vertically pointing radar is proportional to $\exp \left(-\sin ^{2} \theta / \sin ^{2} \theta_{o}\right)$ and the polar diagram of the return from the scatterers is proportional to $\exp \left(-\sin ^{2} \theta / \sin ^{2} \theta_{s}\right)$, where $\theta_{s}$ can be derived from the power $P(\theta)$ received for two zenith angles $\theta_{1}$ and $\theta_{2}$ using an expression derived by Hooper and Thomas (1995) from relations given by Hocking et al. (1986):

$$
\theta_{s}=\arcsin \sqrt{\frac{\sin ^{2} \theta_{2}-\sin ^{2} \theta_{1}}{\ln \left[P\left(\theta_{1}\right) / P\left(\theta_{2}\right)\right]}-\sin ^{2} \theta_{o}} \text {. }
$$

In deriving $\theta_{\mathrm{S}}$ values appropriate to a zenith angle of $6^{\circ}$, power measurements at zenith angles of $4.2^{\circ}$ and $8.5^{\circ}$ were employed. Hooper and Thomas (1995) have previously shown that power measurements at these angles and at $6^{\circ}$ are often consistent with a single value of $\theta_{s}$.

Figure 6 shows comparisons of wind profiles derived from balloon measurements and radar soundings on 23 April 1993 and 4 October 1993. For each of these days, the balloon passed within $\pm 20^{\circ}$ of the AberporthAberystwyth direction, the winds being associated with
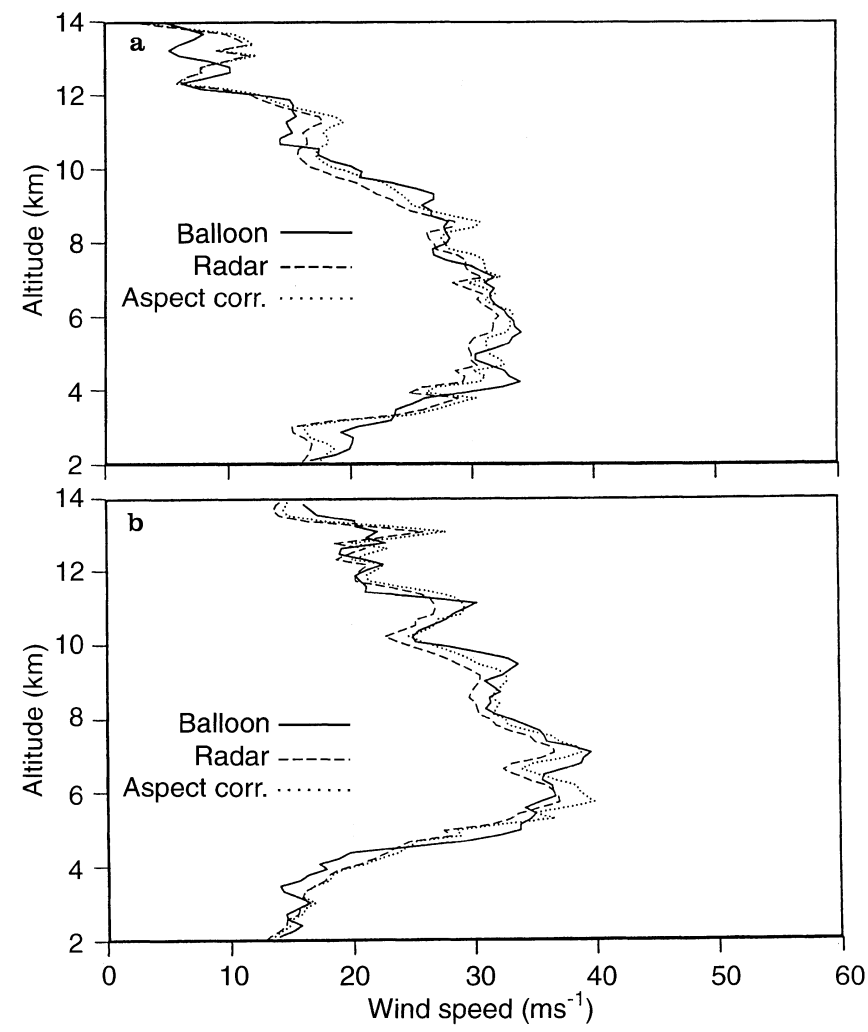

Fig. 6a, b. Profiles of wind speed in the 4-14-km height range derived from radar measurements at Aberystwyth $\left(52.4^{\circ}, 4.1^{\circ} \mathrm{W}\right)$ and radiosondes launched from Aberporth, some $50 \mathrm{~km}$ to the SouthWest, near 0600 GMT on a 23 April 1993 and b 4 October 1993. Also shown are the radar wind profiles derived from the appropriate profiles of effective radar beam zenith angle, $\theta_{\text {eff }}$ 
low-pressure systems located to the North-East of the UK and near South-East Iceland, respectively. In each case, both the initial radar profile and that derived using the calculated height profile of $\theta_{\text {eff }}$ are shown. It is seen that the aspect corrected profile provides better agreement with the balloon measurements over the height ranges $4.5-7 \mathrm{~km}$ and $9-10.5 \mathrm{~km}$ on 23 April (Fig. 6a), but between 7 and $9 \mathrm{~km}$ and also 10.5 and $11.5 \mathrm{~km}$ the correction actually enhances the positive discrepancy, and below $4 \mathrm{~km}$ has little effect. For 4 October, (Fig. 6b), the aspect correction of the radar measurements improves the agreement with the balloon values over heights of $6.5-11 \mathrm{~km}$ but has little effect below about $5 \mathrm{~km}$. Such comparisons of radar and balloon measurements for several individual days show that the correction for aspect sensitivity can improve the agreement between the radar and balloon measurements over limited height ranges. However, it is clear that comparisons of measurements on individual days will be influenced by random errors arising out of a number of factors including spatial and temporal differences, and the sampling procedures and errors of measurement outlined in Sect. 1.

The overall effect of applying the aspect correction to radar measurements on the days on which power measurements were available at zenith angles of $4.2^{\circ}$ and $8.5^{\circ}$ and balloon trajectories passed within $\pm 20^{\circ}$ of the Aberporth-Aberystwyth direction, is illustrated in Fig. 7. This shows comparisons of balloon wind speeds with uncorrected and corrected radar wind speeds, based on 18 balloon flights, for the height range of 4-14 km after outliers have been removed and the regression lines are constrained to pass through the origin, as described previously. The plots each include a total of about 1100 points. The regression coefficient for the comparison prior to correction for aspect, 0.961 \pm 0.002 , is reasonably consistent with the values shown for this height range in Table 1 . The corresponding result after correction was $1.013 \pm 0.002$, implying that the inclusion of aspect sensitivity removes the $4 \%$ bias and actually results in a small overestimate of the radarbased speeds compared with those from radiosondes, as indicated in the slope of the regression line in Fig.7b.

As already mentioned, these comparisons relate to balloons passing within $\pm 20^{\circ}$ of the Aberporth-Aberystwyth direction to minimise the effect of spatial variations. However, if this restriction on balloon trajectory direction is removed, a similar improvement is found in the balloon and radar wind comparison when the aspect correction based on power measurements at $4.2^{\circ}$ and $8.5^{\circ}$ zenith angles is included. For example, the regression coefficients for the $4-14-\mathrm{km}$ height range, based on about 2820 points from a total of 47 balloon flights, before and after correction are 0.951 \pm 0.002 and $1.000 \pm 0.002$, respectively. It seems, therefore, that the spatial separation of the balloon trajectories and the radar in the present study makes no significant contribution to the systematic difference between wind speeds observed by the two techniques, the influence of the aspect sensitivity at $6^{\circ}$ zenith angles having a dominant influence. However, the separation
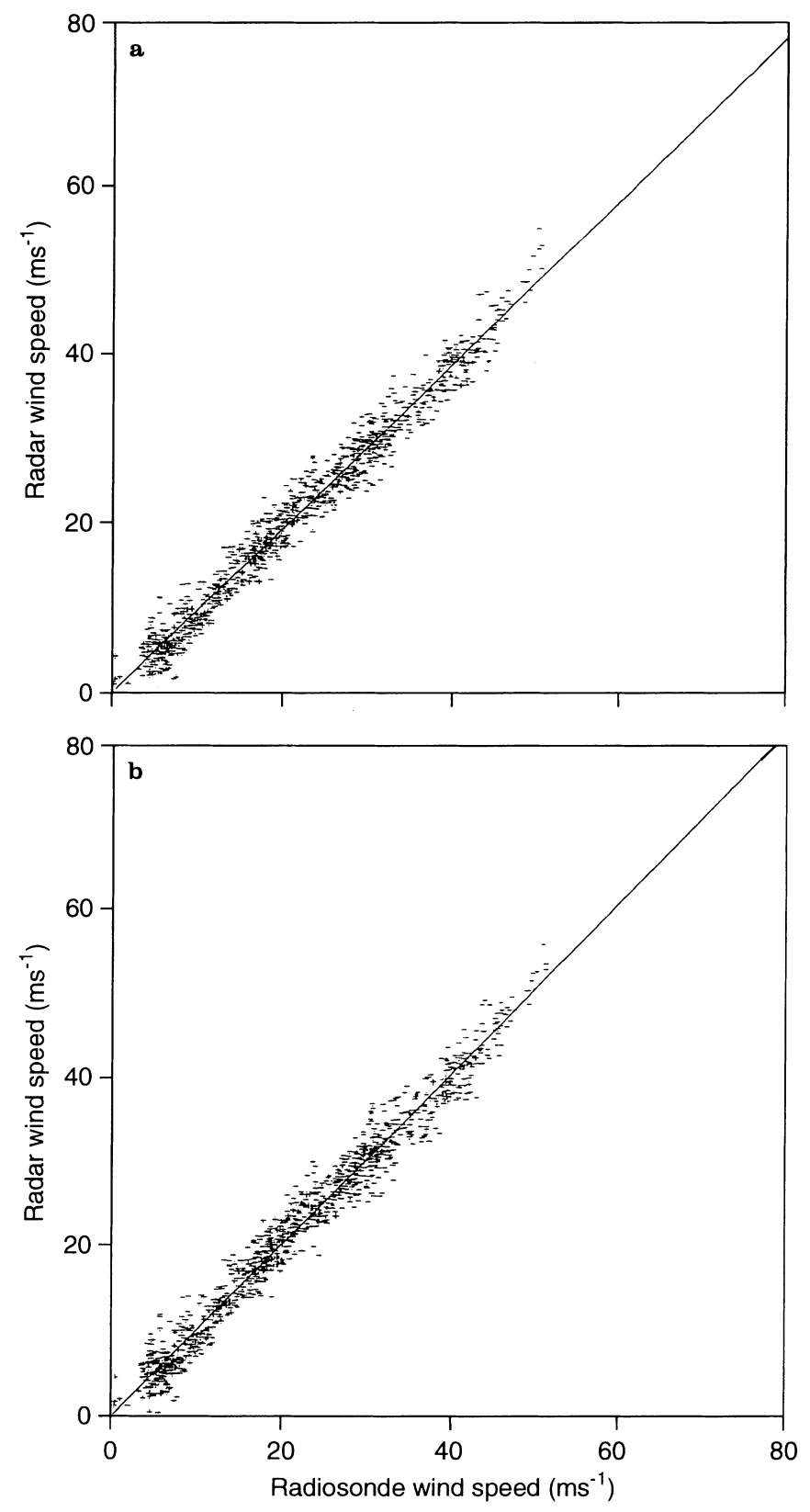

Fig. 7a,b. Comparison of wind speed in the $4-14-\mathrm{km}$ height range derived from simultaneous radar measurements and 18 radiosonde flights passing within $\pm 20^{\circ}$ of Aberporth-Aberystwyth line a assuming the $6^{\circ}$ nominal radar beam zenith angle and $\mathbf{b}$ adopting the effective radar beam zenith angles, $\theta_{\text {eff }}$

would certainly contribute to the random differences between the two types of measurement, as has been demonstrated in comparisons of radiosonde measurements [Sect. 3.2; Jasperson, 1982; Kitchen, 1989).

\section{Discussion}

In the present study, radar and radiosonde wind data extending over 2 years and covering all conditions and seasons were used in order to include a range of climatic conditions. It is clear that the comparisons would cover 
periods when the two instruments could be measuring very different winds because of meteorological variability, but it seems that much of this data would be removed by the exclusion of outliers (Sect. 3.2). Because of the locations of the Aberporth radiosonde station and the radar system near the West coast of Wales, it might have been expected that temporal and spatial variations in the lee of mountains could be significant. In this connection, it has been found that large vertical velocities above the radar site associated with mountain waves are commonly associated with both westerly and easterly low-level winds (Prichard et al., 1995). However, as mentioned in Sect. 3.5, large vertical velocities associated with such waves seem to have little influence on the systematic difference between radar and balloon wind speeds.

From Sect. 4 it appears that the error in the effective pointing angle arising from the aspect sensitivity of echoes observed at a nominal zenith angle of $6^{\circ}$ is largely responsible statistically for the underestimates in the radar measurements of wind speeds compared with those derived from radiosondes; the comparisons for individual days are influenced by random errors but the application of the pointing angle correction is found to improve the agreement between the radar and balloon measurements over limited height ranges. Steinhagen et al. (1994) have reported that the application of an aspect sensitivity correction, by means of Eqs. 1 and 2, resulted in good agreement between average radar profile measurements and radiosonde data over a 12-day period. However, in applying this correction they used power measurements at the nominal zenith angle of $7^{\circ}$ used for the wind measurements and in the vertical direction. From a comparison of radiosonde and radar wind measurements, using vertical and $6^{\circ}$ off-vertical beam directions as in the present study, Astin and Thomas (1991) estimated effective beam pointing angles. The corresponding angles derived from a comparison of echo power measurements in the vertical and $6^{\circ}$ offvertical directions showed marked discrepancies. As demonstrated by Hooper and Thomas (1995), the use of the power in the vertical direction will generally provide too small a value of $\theta_{s}$ from Eq. 2, then too small a value of $\theta_{\text {eff }}$ from Eq. 1, and, hence, too large a correction to the horizontal wind speeds.

The selection of balloon trajectories to be within $\pm 20^{\circ}$ of the Aberporth-Aberystwyth direction in Sects. 3.3 and 3.4 implies that the wind was close to the $27.7^{\circ}$ East of North azimuth of one of the radar beam directions used in the wind measurement, and approximately perpendicular to that at $297.7^{\circ}$ East of North azimuth. From the regression coefficients derived for these two azimuths, in Table 1, it is seen that the discrepancy for most height ranges is generally larger in the latter azimuth. If the underestimates of radar wind speeds are, indeed, due to the effect of aspect sensitivity, the relatively larger discrepancy in the direction approximately transverse to the mean wind would seem to be inconsistent with the report of Yoe et al. (1994) that the aspect sensitivity is more marked for radar beams directed parallel to the horizontal flow in jet streams than in other beam directions. However, these workers, like Steinhagen et al. (1994), based their assessment of aspect sensitivity on considerations of power measurements at zenith angles of $7^{\circ}$ and the vertical. A parallel study here has shown that although the power at zenith angles of $4.2^{\circ}, 6^{\circ}$ and $8.5^{\circ}$ sometimes showed a dependence on azimuth, the ratio of powers at $4.2^{\circ}$ and $8.5^{\circ}$ at such times did not. Therefore, the ratio of such powers at the intermediate azimuth $342.7^{\circ}$ East of North provided an appropriate value of $\theta_{\text {eff }}$. It is to be noted also that whereas the study of Yoe et al. (1994) was directed towards jet-stream conditions, the present statistical study relates to all conditions over a 2-year period.

Of the other reports of underestimates of radar wind measurements compared with balloon values, the most striking is that of Kessler et al. (1986). Radar wind observations at $50 \mathrm{MHz}$ were used in a total of 50 comparisons with radiosonde wind measurements, showing very substantial underestimates in wind speed but generally good agreement in wind direction. For these measurements, the nominal zenith angles employed were near $15^{\circ}$ and the effect of aspect sensitivity would not be expected at such large angles. An extensive comparison over a 2-year period of radar measurements at $915 \mathrm{MHz}$ and radiosonde measurements of wind velocity has been described by Weber and Wuertz (1990). They report that the wind profiler measurements gave average wind speeds $0.5-1.0 \mathrm{~m} \mathrm{~s}^{-1}$ lower than the radiosonde measurements. Sato and Woodman (1982) have stated that aspect sensitivity is not important at $430 \mathrm{MHz}$. The higher frequency of the radar of Weber and Wuertz, and their use of beam zenith angle of $15^{\circ}$, would therefore seem to rule out aspect sensitivity as an explanation for their smaller underestimates of radar wind speed.

\section{Conclusions}

Horizontal wind speeds, derived from radar measurements at nominal zenith angles of $6^{\circ}$ and in the vertical direction over a 2 -year period show underestimates of 4-6\% compared with simultaneous radiosonde values. A comparison of the radar and radiosonde measurements in the two orthogonal azimuths employed in the radar measurements has revealed that similar biases occur in the wind components in these two azimuths, which is consistent with the good agreement shown by the radar and radiosonde measurements of wind direction. Comparisons based on selected balloon trajectories have shown that the underestimate is not due to the separation of the two types of measurement. It is also shown that any uncertainty in the vertical velocity makes no significant contribution to the bias. The aspect sensitivity at a zenith angle of $6^{\circ}$ has been examined using co-ordinated measurements of radar echo power at $4.2^{\circ}$ and $8.5^{\circ}$. It is found that the correction of the nominal zenith angle for this aspect sensitivity provides improved agreement between the radar and balloon wind speeds, both statistically and for certain height ranges on individual days. 
Acknowledgements. The MST radar used in this study is a Natural Environment Research Council facility. The authors are indebted to the Meteorological Office for the award of a Gassiot Studentship to one of us (RMW) and for the provision of radiosonde data.

Topical Editor L. Eymord thanks J. Van Baelen and T. Sato for their help in evaluating this paper.

\section{References}

Astin, I. and L. Thomas, The accuracy and precision of radar wind measures, Proc. Fifth Workshop on Technical and Scientific Aspects of MST Radar, Ed. B. Edwards, SCOSTEP, University of Illinois, Urbana, USA, pp. 15-20, 1991.

Balsley, B. B., W. L. Ecklund, D. A. Carter, and P. E. Johnston, The Poker Flat MST radar. First results, Geophys. Res. Lett., 6, 921-924, 1979.

Crane, R. K., Radar measurements of wind at Kwajalein, Radio Sci., 15, 383-394, 1980.

Ecklund, W. L., D. A. Carter, and B. B. Balsley, Continuous measurement of upper atmospheric winds and turbulence using a VHF Doppler radar. Preliminary results, J. Atmos. Terr. Phys., 41, 983-994, 1979.

Farley, D. T., B. B. Balsley, W. E. Swartz, and C. La Hoz, Tropical winds measured by the Arecibo radar, J. Appl. Meteorol., 18, 227-230, 1979.

Fukao, S., T. Sato, N. Yamasaki, R. M. Harper, and S. Kato, Winds measured by a UHF Doppler radar and rawinsodes: Comparisons made on twenty-six days (August-September 1977) at Arecibo, Puerto Rico, J. Appl. Meteorol., 21, 13571363, 1982.

Gage, K. S., and J. L. Green, Evidence for specular reflection from monostatic VHF radar observations of the stratosphere, Radio Sci., 13, 991-1001, 1978.

Golley, M. G., and D. E. Rossiter, Some tests of methods of analysis of ionospheric drift records using an array of 89 aerials, J. Atmos. Terr. Phys., 32, 1215-1233, 1970.

Green, J. L., J. M. Warnock, R. H. Winkler, and T. E. VanZandt, Studies of winds in the upper troposphere with a sensitive VHF radar, Geophys. Res. Lett., 2, 19-21, 1975.

Hasenjäger, H., What is COST? Meteorol. Rundsch., 42, 69-70, 1990.

Hocking, W. K., R. Rüster, and P. Czechowsky, Absolute reflectivities and aspect sensitivities of VHF radio wave scatterers measured with the SOUSY radar, J. Atmos. Terr. Phys., 48, 131-144, 1986.

Hooper, D., and L. Thomas, Aspect sensitivity of VHF scatterers in the troposphere and stratosphere from comparisons of powers in off-vertical beams, J. Atmos. Terr. Phys., 57, 655-663, 1995.

Jasperson, W. H., Mesoscale time and space wind variability, $J$. Appl. Meteorol., 21, 831-839, 1982.

Kessler, E., M. Eilts, and K. Thomas, A look at profiler performance, Proc. Third Workshop on Technical and Scientific Aspects of MST radar, (Eds.), S.A. Bohill and B. Edwards, SCOSTEP, University of Illinois, Urbana, USA. pp. 72-84, 1986.
Kitchen, M., Representativeness errors for radiosonde observations, Q.J.R. Meteorol. Soc., 115, 673-700, 1989.

Larsen, M. F., Can a VHF Doppler radar provide synoptic wind data? A comparison of 30 days of radar and radiosonde data, Mon. Weather Rev., 111, 2047-2057, 1983.

May, P. T., Comparison of wind-profiler and radiosonde measurements in the tropics, J. Atmos. Oceanic Technol., 10, 122127, 1993.

Prichard, I. T., L. Thomas, and R. M. Worthington, The characteristics of mountain waves observed by radar near the west coast of Wales, Ann. Geophysicae, 13, 757-767, 1995.

Röttger, J., Investigations of lower and middle atmosphere dynamics with spaced antenna drifts radars, J. Atmos. Terr. Phys., 43, 277-292, 1981.

Röttger, J., J. Klostermeyer, P. Czechowsky, R. Rüster, and G. Schmidt, Remote sensing of the atmosphere by VHF radar experiments, Naturwissenschaften, 65, 285-296, 1978.

Röttger. J., and C. H. Liu, Partial reflection and scattering of VHF radar signals from the clear atmosphere, Geophys. Res. Lett., 5, 357-360, 1978.

Sato, T., and R. F. Woodman, Fine altitude resolution observations of stratospheric turbulent layers by the Arecibo $430 \mathrm{MHz}$ radar, J. Atmos.Sci., 39, 2546-2552, 1982.

Seraphin, R. J., and W. F. Dabberdt, Profiling networks and developments in the United States, Meteorol. Rundsch., 42, 7083, 1990.

Steinhagen, H., A. Christoph, P. Czechowsky, U. Gördsdorf, M. Gube-Lenhardt, J. Lippmann, J. Neisser, R. Rüster, G. Schmidt, W. Wergen, and J. G. Yoe. Field campaign for the comparison of SOUSY radar wind measurements with rawinsonde and model data, Ann. Geophysicae, 12, 746-764, 1994.

Strauch, R. G., D. A. Merritt, K. P. Moran, K. P. Earnshaw, and D. W. Van de Kamp, The Colorado wind profiling network, $J$. Atmos. Oceanic Technol., 1, 37-49, 1984.

Tsuda, T., T. Sato, K. Hirose, S. Fukao, and S. Kato, MU radar observations of the aspect sensitivity of backscattered VHF echo power in the troposphere and lower stratosphere, Radio Sci., 21, 971-980, 1986.

Van Baelen, J. S., T. Tsuda, A. D. Richmond, S. K. Avery, S. Kato, S. Fukao, and M. Yamamoto, Comparisons of VHF Doppler beam swinging and spaced antenna observations with the MU radar: First results, Radio Sci., 25, 629-640, 1990.

Vincent, R. A., P. T. May, W. K. Hocking, W. G. Elford, B. H. Candy, and B. H. Briggs, First results with the Adelaide VHF radar. Spaced antenna studies of tropospheric winds, J. Atmos. Terr. Phys., 49, 353-366, 1987.

Warnock, J. M., T. E. VanZandt, J. L. Green, and R. H. Winkler, Comparison between wind profiles measured by Doppler radar and by rawinsonde balloons, Geophys. Res. Lett., 5, 109-112, 1978.

Weber, B. L., and D. B. Wuertz, Comparison of rawinsonde and wind profiler radar measurements, J. Atmos. Oceanic Technol., 7, 157-174, 1990.

Yoe, J. G., P. Czechowsky, R. Rüster, and G. Schmidt, Spatial variability of the aspect sensitivity of VHF radar echoes in the troposphere and lower stratosphere during jet stream passages, Ann. Geophysicae, 12, 733-745, 1994. 